\title{
Improvement in Exercise Capacity by Exercise Training Associated With Favorable Clinical Outcomes in Advanced Heart Failure With High B-Type Natriuretic Peptide Level
}

\author{
Michio Nakanishi, MD; Kazuhiro Nakao, MD; Leon Kumasaka, MD; Tetsuo Arakawa, MD; \\ Shigefumi Fukui, MD; Takahiro Ohara, MD; Masanobu Yanase, MD; \\ Teruo Noguchi, MD; Satoshi Yasuda, MD; Yoichi Goto, MD
}

Background: The efficacy of exercise training (ET) programs and its relationship with long-term clinical outcomes in advanced heart failure (HF) patients with high levels of B-type natriuretic peptide (BNP) remain uncertain.

\begin{abstract}
Methods and Results: We studied 340 consecutive HF patients with ejection fraction (EF) $<45 \%$ who completed a 3-month ET program. Patients with BNP $\geq 200 \mathrm{pg} / \mathrm{mL}$ (High-BNP, $\mathrm{n}=170$ ) had more advanced HF characteristics, including lower $\mathrm{EF}(25.0 \pm 8.6 \%$ vs. $28.1 \pm 8.0 \%, P=0.0008)$, than those with $B N P<200 \mathrm{pg} / \mathrm{mL}$. In the High-BNP patients, peak oxygen uptake $\left(\mathrm{V}_{2}\right)$ was significantly increased by $8.3 \pm 16.2 \%$ during the ET program, and changes in peak $\mathrm{VO}_{2}$ inversely correlated with changes in $\mathrm{BNP}(\mathrm{R}=-0.453$, $\mathrm{P}<0.0001)$ and changes in ventilatory efficiency ( $\dot{\mathrm{V} E} / \mathrm{V} \mathrm{CO}_{2}$ slope $)(\mathrm{R}=-0.439, \mathrm{P}<0.0001)$. During a median follow-up of 46 months, patients in the upper tertile of changes in peak $\mathrm{VO}_{2}(\geq 13.0 \%)$, compared with those in the lower tertile $(<1.0 \%)$, had lower rates of the composite of all-cause death or HF hospitalization ( $37.9 \%$ vs. $54.4 \%, \mathrm{P}=0.036)$ and all-cause death $(8.6 \%$ vs. $24.6 \%, \mathrm{P}=0.056)$. In the multivariate analysis, change in peak $\mathrm{V}_{2}$ was a significant independent predictor of the composite outcome and all-cause death.
\end{abstract}

Conclusions: Even among advanced HF patients with high BNP level, an ET program significantly improved exercise capacity, and a greater improvement in exercise capacity was associated with greater decreases in $\mathrm{BNP}$ level and $\mathrm{V} E / \mathrm{V} \mathrm{CO}_{2}$ slope and more favorable long-term clinical outcomes.

Key Words: Exercise capacity; Exercise training; Heart failure; Natriuretic peptides; Oxygen uptake

$\mathbf{H}$ eart failure (HF) is a major public health problem with high morbidity and mortality. Despite recent advances in pharmacological and non-pharmacological treatments, the prognosis in patients with HF remains poor. ${ }^{1,2}$ In HF patients, exercise capacity, as measured by peak oxygen uptake $\left(\mathrm{V}_{2}\right)$, is an established strong prognostic predictor, ${ }^{3}$ and an increase over time in exercise capacity has been shown to be associated with a favorable clinical outcome.,45 Exercise training (ET) improves exercise capacity in HF patients, ${ }^{6-9}$ and is recommended by current HF practice guidelines at a Class I level. ${ }^{10,11}$ However, the association between baseline patient characteristics and the efficacy of ET programs has not been fully elucidated.

The plasma B-type natriuretic peptide (BNP) level is a reliable and established prognostic biomarker, and HF patients with a high BNP level have a poor prognosis. ${ }^{12,13}$ In such advanced HF patients, it remains uncertain whether an ET program can safely improve exercise capacity or whether an improvement in exercise capacity by ET program will lead to favorable long-term clinical outcomes.

The purpose of the present study was to evaluate the efficacy of an ET program and its relationship with longterm clinical outcomes in advanced HF patients with high BNP level $(\geq 200 \mathrm{pg} / \mathrm{mL})$ and receiving current optimal medical therapy.

\section{Methods}

\section{Study Population}

Consecutive HF patients who participated in a 3-month ET program between January 2002 and October 2015 at our institution were screened retrospectively. HF patients were eligible for the ET program if they met any of 3criteria (left ventricular ejection fraction $[\mathrm{LVEF}] \leq 40 \%$, percent-predicted peak $\mathrm{VO}_{2} \leq 80 \%$, and BNP level $\geq 80 \mathrm{pg} / \mathrm{mL}$ ), and were referred to the program at their physicians' discretion. We included patients who completed the ET pro-

Received December 13, 2016; revised manuscript received March 11, 2017; accepted March 15, 2017; released online April 20, 2017 Time for primary review: 23 days

Department of Cardiovascular Medicine, National Cerebral and Cardiovascular Center, Suita, Japan

Mailing address: Yoichi Goto, MD, Department of Cardiovascular Medicine, National Cerebral and Cardiovascular Center, 5-7-1 Fujishiro-dai, Suita 565-8565, Japan. E-mail: ygoto@hsp.ncvc.go.jp

ISSN-1346-9843 All rights are reserved to the Japanese Circulation Society. For permissions, please e-mail: cj@j-circ.or.jp 


\begin{tabular}{|c|c|c|c|c|}
\hline Characteristic & $\begin{array}{l}\text { All patients } \\
(n=340)\end{array}$ & $\begin{array}{c}\text { BNP }<200 \mathrm{pg} / \mathrm{mL} \\
(\mathrm{n}=170)\end{array}$ & $\begin{array}{c}B N P \geq 200 \mathrm{pg} / \mathrm{mL} \\
(n=170)\end{array}$ & P value* \\
\hline Age (years) & $62.1 \pm 13.5$ & $60.4 \pm 12.4$ & $63.8 \pm 14.4$ & 0.023 \\
\hline Male & 265 (77.9) & $137(80.6)$ & $128(75.3)$ & 0.24 \\
\hline Hypertension & $188(55.3)$ & $98(57.7)$ & $90(52.9)$ & 0.38 \\
\hline Diabetes & $128(37.7)$ & $62(36.5)$ & $66(38.8)$ & 0.65 \\
\hline BMI & $22.0 \pm 3.6$ & $22.4 \pm 3.8$ & $21.6 \pm 3.2$ & 0.025 \\
\hline $\mathrm{IHD}$ & $147(43.2)$ & $61(35.9)$ & $86(50.6)$ & 0.0061 \\
\hline AF rhythm & $58(17.1)$ & $27(15.9)$ & $31(18.2)$ & 0.56 \\
\hline Serum creatinine $(\mathrm{mg} / \mathrm{dL})$ & $1.08 \pm 0.39$ & $1.01 \pm 0.33$ & $1.15 \pm 0.43$ & 0.0009 \\
\hline Hemoglobin (g/dL) & $13.2 \pm 1.7$ & $13.6 \pm 1.6$ & $12.8 \pm 1.7$ & $<0.0001$ \\
\hline Plasma BNP (pg/mL) & $270.9 \pm 256.8$ & $106.2 \pm 53.6$ & $435.7 \pm 273.4$ & $<0.0001$ \\
\hline LVDd (mm) & $62.9 \pm 9.0$ & $61.2 \pm 8.5$ & $64.6 \pm 9.3$ & 0.0006 \\
\hline LVDs (mm) & $53.5 \pm 10.5$ & $51.4 \pm 9.7$ & $55.6 \pm 10.8$ & 0.0002 \\
\hline LVEF (\%) & $26.5 \pm 8.5$ & $28.1 \pm 8.0$ & $25.0 \pm 8.6$ & 0.0008 \\
\hline LAD (mm) & $44.5 \pm 8.0$ & $43.4 \pm 8.2$ & $45.6 \pm 7.7$ & 0.013 \\
\hline \multicolumn{5}{|l|}{ Medications } \\
\hline$\beta$-blocker & 324 (95.3) & $164(96.5)$ & $160(94.1)$ & 0.30 \\
\hline ACEI or ARB & $276(81.2)$ & $134(78.8)$ & $142(83.5)$ & 0.27 \\
\hline Diuretic & $262(77.1)$ & $115(67.7)$ & $147(86.5)$ & $<0.0001$ \\
\hline \multicolumn{5}{|l|}{ CPX parameters } \\
\hline Peak RER & $1.26 \pm 0.13$ & $1.26 \pm 0.13$ & $1.26 \pm 0.13$ & 0.94 \\
\hline Peak work rate $(\mathrm{W})$ & $92.7 \pm 31.8$ & $102.0 \pm 34.0$ & $83.5 \pm 26.5$ & $<0.0001$ \\
\hline Peak $\dot{V O}_{2}(\mathrm{~mL} / \mathrm{kg} / \mathrm{min})$ & $17.7 \pm 4.7$ & $19.0 \pm 5.0$ & $16.4 \pm 4.2$ & $<0.0001$ \\
\hline \% Predicted peak $\mathrm{VO}_{2}(\%)$ & $63.8 \pm 15.4$ & $66.7 \pm 15.8$ & $61.0 \pm 14.4$ & 0.0007 \\
\hline$\dot{\mathrm{VE}} / \dot{\mathrm{VCO}}{ }_{2}$ slope & $33.3 \pm 7.4$ & $30.9 \pm 5.7$ & $35.6 \pm 8.2$ & $<0.0001$ \\
\hline
\end{tabular}

Variables are expressed as mean $\pm \mathrm{SD}$ or $\mathrm{n}(\%)$. ${ }^{*}$ For comparison of $\mathrm{BNP}<200 \mathrm{pg} / \mathrm{mL} \mathrm{vs}$. BNP $\geq 200 \mathrm{pg} / \mathrm{mL}$. ACEI, angiotensin-convertingenzyme inhibitor; AF, atrial fibrillation or flutter; ARB, angiotensin-receptor blocker; BMI, body mass index (weight in kilograms divided by the square of the height in meters); BNP, B-type natriuretic peptide; CPX, cardiopulmonary exercise testing; IHD, ischemic heart disease; LAD, left atrial diameter; LVDd, left ventricular end-diastolic diameter; LVDs, left ventricular end-systolic diameter; LVEF, left ventricular ejection fraction; RER, respiratory exchange ratio; $\dot{\mathrm{V}} \mathrm{CO}_{2}$, carbon dioxide production; $\dot{\mathrm{V}} \mathrm{E}$, minute ventilation; $\dot{\mathrm{V}} \mathrm{O}_{2}$, oxygen uptake.

gram and underwent cardiopulmonary exercise testing (CPX) at the beginning and end of the program. Patients were excluded from the study if they had LVEF $\geq 45 \%$, serum creatinine $>2.5 \mathrm{mg} / \mathrm{dL}$, a history of a myocardial infarction (MI) within the previous 3 months, or significant pulmonary, cerebrovascular, or orthopedic disease. Among 455 consecutive patients who entered the 3-month ET program during the study period, 6 patients were hospitalized for worsening HF without any apparent relationship to ET during the 3-month program, and 109 did not undergo the 3-month CPX mostly for social reasons such as remote residence or lack of time. Therefore, we studied 340 patients who completed the 3-month ET program with CPX data at both the beginning and the end. The presence of ischemic heart disease was shown by coronary angiography or documentation of a MI. Treatment for HF was tailored to all patients on the basis of current guidelines and was kept constant throughout the study period. The study complied with the Declaration of Helsinki, was approved by the institutional ethics committee, and all patients gave written informed consent.

\section{ET Program}

At a clinically stable stage after treatment with appropriate medications, the 3-month ET program was started with supervised in-hospital sessions consisting of walking, bicycle ergometer, and low-intensity resistance training for 20-40 min per session 3-5 times per week, followed by home ET combined with once or twice per week supervised in-hospital ET sessions, as previously described. ${ }^{14,15}$ The duration of the exercise was increased to $30-60 \mathrm{~min}$, and the intensity of the endurance exercise was determined individually at a heart rate corresponding to $40-60 \%$ of heart rate reserve (maximal heart rate minus resting heart rate) or anaerobic threshold level obtained in baseline CPX, or at level 12-13 ('a little hard') of the 6-20 scale perceived rating of exercise (original Borg's scale). After completing the 3-month ET program, all patients were encouraged to continue home ET with an individualized exercise prescription on the basis of the CPX result at 3 months.

\section{Cardiopulmonary Exercise Testing}

Symptom-limited CPX was performed using a cycle ergometer with respiratory gas exchange analysis at the beginning and the end of the 3-month ET program. The test consisted of an initial 2 min of rest, 1 min of warm-up ( $0 \mathrm{~W}$ load), and full exercise by an individualized ramp protocol with increments of $10-15 \mathrm{~W} / \mathrm{min}$. Expired gas analysis was performed throughout CPX on a breath-bybreath basis and the minute ventilation $(\dot{\mathrm{VE}}), \dot{\mathrm{VO}}_{2}$, and carbon dioxide production $\left(\dot{\mathrm{V}}^{\mathrm{CO}} 2\right)$ data were stored in a computer hard disk every $6 \mathrm{~s}$ for off-line analysis (AE300S, Minato Medical Science, Osaka, Japan). Based on the findings previously described, ${ }^{16}$ all subjects undergoing CPX had been strongly encouraged to exercise towards exhaustion with a target peak respiratory exchange ratio 
Table 2. Change in Major Variables During 3-Month ET Program

\begin{tabular}{|c|c|c|c|c|c|c|}
\hline & \multicolumn{3}{|c|}{ All patients $(n=340)$} & \multicolumn{3}{|c|}{ Patients with BNP $\geq 200 \mathrm{pg} / \mathrm{mL}(\mathrm{n}=170)$} \\
\hline & Baseline & 3 months & $P$ value & Baseline & 3 months & $P$ value \\
\hline Creatinine (mg/dL) & $1.08 \pm 0.38$ & $1.12 \pm 0.43$ & 0.16 & $1.15 \pm 0.43$ & $1.21 \pm 0.49$ & 0.25 \\
\hline $\mathrm{BNP}(\mathrm{pg} / \mathrm{mL})$ & $273.6 \pm 259.5$ & $248.8 \pm 262.2$ & 0.22 & $437.8 \pm 275.2$ & $383.0 \pm 298.6$ & 0.082 \\
\hline Peak RER & $1.26 \pm 0.13$ & $1.27 \pm 0.12$ & 0.67 & $1.26 \pm 0.13$ & $1.26 \pm 0.12$ & 0.96 \\
\hline Peak $\dot{\mathrm{VO}} 2$ (mL/kg/min) & $17.7 \pm 4.7$ & $19.0 \pm 5.6$ & 0.0014 & $16.4 \pm 4.2$ & $17.6 \pm 5.3$ & 0.024 \\
\hline V̇E/V்CO 2 slope & $33.3 \pm 7.4$ & $32.8 \pm 7.5$ & 0.39 & $35.6 \pm 8.2$ & $35.0 \pm 8.1$ & 0.49 \\
\hline
\end{tabular}

ET, exercise training. Other abbreviations as in Table 1.

\begin{tabular}{|c|c|c|c|c|}
\hline \multirow[b]{2}{*}{ Characteristic } & \multicolumn{3}{|c|}{ \% Change in peak $\mathrm{V}_{2}$} & \multirow[b]{2}{*}{$P$ value } \\
\hline & $\begin{array}{l}<1.0 \% \\
(n=57)\end{array}$ & $\begin{array}{c}\geq 1.0 \% \text { to }<13.0 \% \\
(n=55)\end{array}$ & $\begin{array}{l}\geq 13.0 \% \\
(n=58)\end{array}$ & \\
\hline Age (years) & $67.6 \pm 12.3$ & $65.1 \pm 14.3$ & $58.7 \pm 15.2$ & 0.0025 \\
\hline Male & $44(77.2)$ & $41(74.6)$ & $43(74.1)$ & 0.92 \\
\hline Hypertension & $36(63.2)$ & $30(54.6)$ & $24(41.4)$ & 0.061 \\
\hline Diabetes & $22(38.6)$ & $27(49.1)$ & $17(29.3)$ & 0.096 \\
\hline BMI & $22.0 \pm 3.1$ & $21.7 \pm 3.2$ & $21.0 \pm 3.2$ & 0.18 \\
\hline IHD & $31(54.4)$ & $30(54.6)$ & $25(43.1)$ & 0.37 \\
\hline AF rhythm & $11(19.3)$ & $10(18.2)$ & $10(17.2)$ & 0.96 \\
\hline Serum creatinine (mg/dL) & $1.19 \pm 0.41$ & $1.20 \pm 0.44$ & $1.06 \pm 0.42$ & 0.12 \\
\hline Hemoglobin (g/dl) & $12.6 \pm 1.6$ & $12.7 \pm 1.7$ & $13.1 \pm 1.7$ & 0.23 \\
\hline Plasma BNP (pg/mL) & $413.8 \pm 220.2$ & $402.1 \pm 255.3$ & $489.0 \pm 328.4$ & 0.18 \\
\hline LVDd (mm) & $64.8 \pm 6.9$ & $63.6 \pm 10.4$ & $65.3 \pm 10.3$ & 0.61 \\
\hline LVDs (mm) & $56.0 \pm 8.4$ & $54.1 \pm 11.9$ & $56.6 \pm 11.8$ & 0.43 \\
\hline LVEF (\%) & $25.5 \pm 8.4$ & $25.9 \pm 8.3$ & $23.7 \pm 9.1$ & 0.34 \\
\hline$\beta$-blocker & $55(96.5)$ & $50(90.9)$ & $55(94.8)$ & 0.45 \\
\hline Diuretic & $49(86.0)$ & $45(81.8)$ & $53(91.4)$ & 0.32 \\
\hline Peak $\dot{V} \mathrm{O}_{2}(\mathrm{~mL} / \mathrm{kg} / \mathrm{min})$ & $16.1 \pm 3.5$ & $16.1 \pm 3.8$ & $17.0 \pm 5.0$ & 0.48 \\
\hline \% Predicted peak $\dot{V O}_{2}(\%)$ & $62.8 \pm 13.1$ & $61.2 \pm 15.1$ & $59.1 \pm 15.0$ & 0.38 \\
\hline$\dot{\mathrm{VE}} / \dot{\mathrm{V} C O} 2$ slope & $35.4 \pm 5.6$ & $36.2 \pm 10.2$ & $35.3 \pm 8.2$ & 0.81 \\
\hline ET session attendance (time) & $18.0 \pm 9.7$ & $19.0 \pm 11.8$ & $19.5 \pm 11.0$ & 0.78 \\
\hline
\end{tabular}

Variables are expressed as mean \pm SD or $n(\%)$. High-BNP=BNP $\geq 200 \mathrm{pg} / \mathrm{mL}$. Abbreviations as in Tables 1,2.

(RER), an objective index of effort adequacy, $>1.20$.

Peak $\dot{\mathrm{VO}}_{2}$ was determined as the higher value of either the greatest $\dot{\mathrm{VO}}_{2}$ during exercise (smoothed after a 5-point moving average) or the average $\dot{\mathrm{VO}}_{2}$ of the last 3 data points (18s) before termination of exercise, and was expressed as a value adjusted to body weight ( $\mathrm{mL} / \mathrm{kg} / \mathrm{min})$. Percent-predicted peak $\mathrm{VO}_{2}(\%)$ was calculated as peak $\dot{\mathrm{VO}}_{2}(\mathrm{~mL} / \mathrm{kg} / \mathrm{min})$ divided by predicted value using the equation: 52.1-0.38 age (years) for men, 40.4-0.23 age (years) for women. The slope of the linear relationship between $\dot{\mathrm{VE}}$ and $\dot{\mathrm{V} C O} 2(\dot{\mathrm{V} E} / \dot{\mathrm{V} C O} 2$ slope), an index of ventilatory efficiency, was determined excluding the part after the respiratory compensation point where the slope started to increase. The change in the peak $\dot{\mathrm{VO}}_{2}$ and $\dot{\mathrm{V}} / \dot{\mathrm{VCO}}_{2}$ slope was determined as the percentage change in the value from baseline to 3 months.

\section{Non-CPX Parameters}

All patients underwent an echocardiographic evaluation in a clinically stable state, and LV end-diastolic diameter (LVDd), and end-systolic diameter (LVDs), and left atrial diameter (LAD) were determined by $2 \mathrm{D}$ echocardiogra- phy. LVEF was measured by echocardiography, radionuclide ventriculography, cardiac magnetic resonance, or LV angiography. In all patients, blood samples were drawn for serum creatinine, hemoglobin and BNP measurements within 3 days of baseline and 3-month CPX. Plasma BNP concentrations were measured by radioimmunoassay (Shionoria BNP kit; Shionogi \& Co. Ltd., Osaka, Japan), and the change in BNP level was determined as the percentage change in the value from baseline to 3 months.

\section{Endpoints}

Follow-up data were determined from outpatient medical records, and at least 1 year of follow-up was available in all patients. Endpoints of this study were the composite outcome (defined as all-cause death or HF hospitalization) and all-cause death, analyzed by time from the date of 3-month CPX to first event. HF hospitalization required that a patient had typical symptoms and signs, treatment with diuretics, and at least an overnight hospital stay.

\section{Data Analysis}

In all patients who met the inclusion criteria, the relation- 


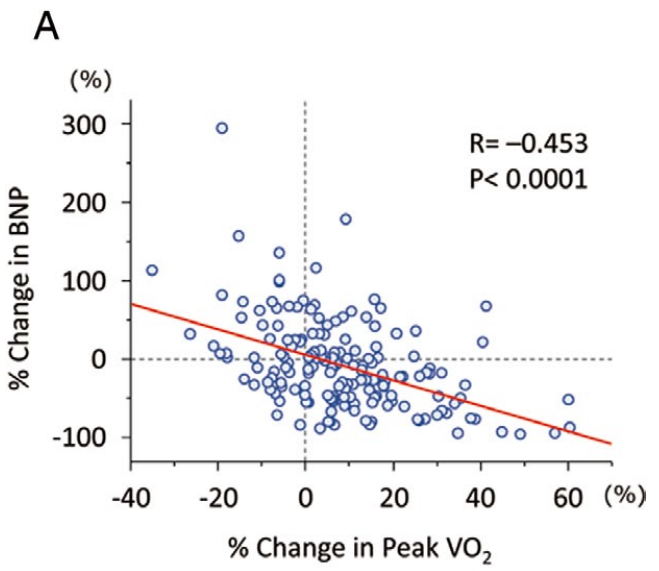

B

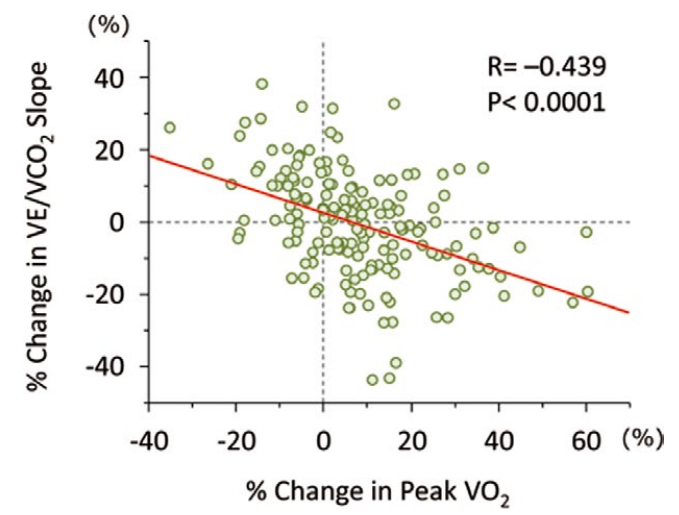

Figure 1. Relationships between changes in peak $\mathrm{VO}_{2}$ and changes in $\mathrm{BNP}$ and $\mathrm{V} E / \mathrm{V} C \mathrm{CO}_{2}$ slope during $\mathrm{ET}$ program in High-BNP patients (BNP $\geq 200 \mathrm{pg} / \mathrm{mL} ; \mathrm{n}=170$ ). Changes in BNP (A) and $\dot{V} E / \mathrm{VCO}_{2}$ slope $(\mathbf{B})$ had a significantly inverse relationship with changes in peak $\mathrm{VO}_{2}$ during the 3-month ET program. BNP, B-type natriuretic peptide; ET, exercise training.

ships between major baseline variables and the change in peak $\dot{\mathrm{VO}}_{2}$ during the 3-month ET program were assessed. In the High-BNP patients, baseline characteristics and clinical outcomes were compared according to tertiles of the percentage change in peak $\mathrm{VO}_{2}$ during the ET program: $<1.0 \%$ (Poor-improvement group), $\geq 1.0 \%$ to $<13.0 \%$ (Modest-improvement group), and $\geq 13.0 \%$ (Markedimprovement group).

\section{Statistical Analysis}

Continuous variables, presented as mean \pm standard deviation, were compared by unpaired Student's t-test and categorical variables by $\chi^{2}$ test. Cumulative events were assessed by the Kaplan-Meier method, and differences in events were compared with a log-rank test. Cox proportional hazard analysis was used to assess the association between variables and outcomes. Variables with a value of $\mathrm{P}<0.1$ in the univariate analysis were included in the multivariate analysis. A value of $\mathrm{P}<0.05$ was considered to be statistically significant.
All-cause Death or HF Hospitalization

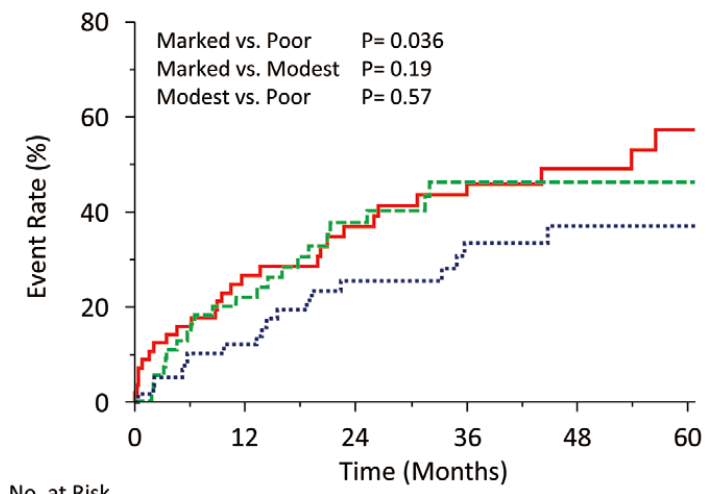

No. at Risk

$\begin{array}{lllllll}\text { Poor } & 57 & 41 & 31 & 25 & 15 & 11 \\ \text { Modest } & 55 & 39 & 26 & 17 & 15 & 14 \\ \text { Marked } & 58 & 50 & 36 & 26 & 18 & 14\end{array}$

B

All-cause Death

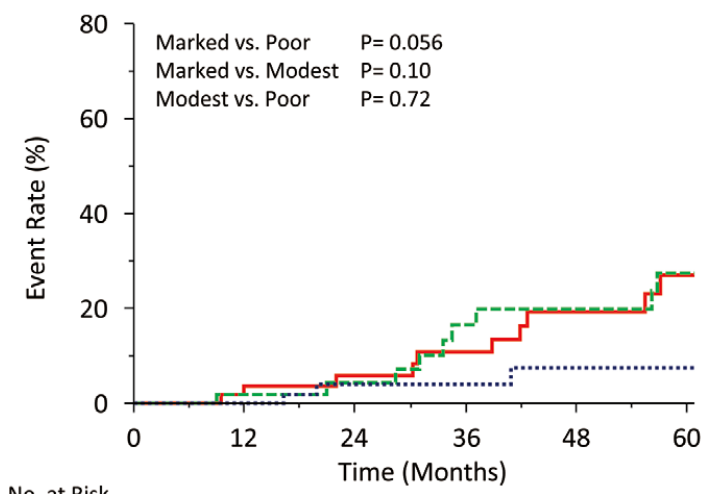

No. at Risk

$\begin{array}{lllllll}\text { Poor } & 57 & 53 & 43 & 36 & 24 & 20 \\ \text { Modest } & 55 & 49 & 37 & 26 & 22 & 19 \\ \text { Marked } & 58 & 56 & 42 & 33 & 22 & 17\end{array}$

Figure 2. Kaplan-Meier curves for the composite outcome and all-cause death according to change in peak $\mathrm{VO}_{2}$ during ET program in High-BNP patients (BNP $\geq 200 \mathrm{pg} / \mathrm{mL} ; \mathrm{n}=170$ ). Composite rate of all-cause death or HF hospitalization $(\mathbf{A})$ and all-cause death (B) were compared according to tertiles of the change in peak $\mathrm{VO}_{2}$ during the 3-month ET program: $<1.0 \%$ (Poor-improvement group), $\geq 1.0 \%$ to $<13.0 \%$ (Modestimprovement group), and $\geq 13.0 \%$ (Marked-improvement group). BNP, B-type natriuretic peptide; ET, exercise training.

\section{Results}

\section{Baseline Characteristics and Efficacy and Safety of the ET Program in All Patients}

From January 2002 through October 2015, 340 patients met the inclusion criteria, and their baseline characteristics are shown in Table 1. The mean age of all patients was 62.1 years, and $78 \%$ were male. Most of the patients (95\%) were treated with $\beta$-blockers. Among them, there were no exercise-related deaths or adverse events requiring hospitalization, including worsening HF, MI, or sustained ventricular tachycardia, during the 3-month ET program. The median 


\begin{tabular}{|c|c|c|c|c|c|}
\hline & \multicolumn{3}{|c|}{ Univariate } & \multicolumn{2}{|c|}{ Multivariate } \\
\hline & $X^{2}$ & HR (95\% Cl) & $P$ value & HR (95\% Cl) & $P$ value \\
\hline Age (years) & 0.078 & $1.00(0.98-1.01)$ & 0.78 & & \\
\hline Male & 0.16 & $1.11(0.67-1.91)$ & 0.69 & & \\
\hline IHD & 0.10 & $0.93(0.60-1.45)$ & 0.75 & & \\
\hline AF rhythm & 0.0034 & $0.98(0.55-1.66)$ & 0.95 & & \\
\hline BMI & 1.2 & $0.96(0.89-1.03)$ & 0.27 & & \\
\hline LVDd (mm) & 4.0 & $1.03(1.0004-1.05)$ & 0.047 & $0.95(0.87-1.03)$ & 0.24 \\
\hline LVDs (mm) & 6.2 & $1.03(1.006-1.05)$ & 0.013 & $1.08(1.002-1.16)$ & 0.043 \\
\hline LVEF (\%) & 0.99 & $0.99(0.96-1.01)$ & 0.32 & & \\
\hline LAD (mm) & 12.1 & $1.05(1.02-1.08)$ & 0.0005 & $1.04(1.01-1.07)$ & 0.014 \\
\hline Creatinine (mg/dL) & 3.4 & $1.62(0.97-2.62)$ & 0.066 & $0.92(0.51-1.63)$ & 0.79 \\
\hline Hemoglobin (g/dL) & 7.1 & $0.82(0.71-0.95)$ & 0.0075 & $0.93(0.79-1.09)$ & 0.37 \\
\hline BNP (per 10-pg/mL) & 9.1 & $1.010(1.004-1.015)$ & 0.0025 & $1.008(1.0001-1.015)$ & 0.047 \\
\hline Baseline peak $\dot{\mathrm{VO}}_{2}(\mathrm{~mL} / \mathrm{kg} / \mathrm{min})$ & 18.4 & $0.87(0.81-0.93)$ & $<0.0001$ & $0.91(0.82-0.99)$ & 0.031 \\
\hline$\%$ Change in peak $\dot{\mathrm{VO}}_{2}(\%)$ & 12.3 & $0.97(0.96-0.99)$ & 0.0004 & $0.97(0.96-0.99)$ & 0.0006 \\
\hline$\dot{\mathrm{VE}} / \mathrm{V} \mathrm{CO}_{2}$ slope & 13.7 & $1.05(1.02-1.07)$ & 0.0002 & $1.02(0.99-1.05)$ & 0.16 \\
\hline ET session attendance (times) & 0.37 & $0.99(0.97-1.01)$ & 0.54 & & \\
\hline
\end{tabular}

High-BNP=BNP $\geq 200 \mathrm{pg} / \mathrm{mL}$. $\mathrm{Cl}$, confidence interval; ET, exercise training; HF, heart failure; HR, hazard ratio. Other abbreviations as in Tables 1,2.

time from baseline to 3-month CPX was 91 days (interquartile range, 84-98). The attained peak RER, an objective index of effort adequacy, was consistently high at both baseline and 3-month CPX. During the 3-month ET program, peak $\dot{\mathrm{VO}}_{2}$ was significantly increased, while creatinine, $\mathrm{BNP}$, and $\dot{\mathrm{VE}} / \dot{\mathrm{V} C O}_{2}$ slope did not change significantly (Table 2). The change in peak $\dot{\mathrm{VO}}_{2}$ during the ET program $(+9.2 \pm 16.0 \%)$ had a significantly inverse relationship with age $(\mathrm{R}=-0.236, \mathrm{P}<0.0001)$, but not with other variables including body mass index (BMI) $(\mathrm{P}=0.053)$, LVDd $(\mathrm{P}=0.75)$, LVEF $(\mathrm{P}=0.14)$, hemoglobin $(\mathrm{P}=0.41)$, and $\mathrm{BNP}$ $(\mathrm{P}=0.89)$.

\section{Baseline Characteristics of High-BNP Patients}

Among the total patients, $170(50 \%)$ comprised the HighBNP group. Baseline characteristics analysis showed that the High-BNP patients, compared with the Low-BNP group $(n=170)$, were older (mean age 63.8 years), had a higher prevalence of ischemic heart disease, lower BMI and hemoglobin, higher serum creatinine, more advanced HF characteristics, including larger LVDd, LVDs, and $\mathrm{LAD}$, lower LVEF and peak $\dot{\mathrm{VO}}_{2}$, and higher $\dot{\mathrm{VE}} / \dot{\mathrm{VCO}}_{2}$ slope, and were more likely to be taking diuretics (Table 1). During a median follow-up of 46 months, the High-BNP patients had significantly higher rates of the composite of all-cause death or HF hospitalization (46.5\% vs. $25.3 \%$, $\mathrm{P}<0.0001)$ and all-cause death $(17.7 \%$ vs. $10.0 \%, \mathrm{P}=0.029)$ than the Low-BNP patients.

\section{Variables Associated With Change in Exercise Capacity in High-BNP Patients}

In the High-BNP patients, peak $\dot{\mathrm{V}}_{2}$ was significantly increased during the 3-month ET program (Table 2), and there was no significant difference in the change in peak $\dot{\mathrm{VO}} 2$ during the ET program between the High-BNP and Low-BNP patients $(+8.3 \pm 16.2 \%$ vs. $+10.1 \pm 15.9 \%$, respectively, $\mathrm{P}=0.31$ ).

When the High-BNP patients were divided according to tertiles of the change in peak $\mathrm{VO}_{2}$ during the ET program (Poor-improvement group, $\mathrm{n}=57$, Modest-improvement group, $n=55$, and Marked-improvement group, $n=58$ ), there were no significant differences among these groups in baseline characteristics, except for age, which was significantly lower in the Marked-improvement group, as compared with the other 2 groups (Table 3). The number of attendances at supervised ET sessions during the ET program was also similar among the 3 groups.

The change in peak $\dot{\mathrm{VO}}_{2}$ during the 3-month ET program was $-7.9 \pm 7.3 \%$ in the Poor-improvement group, $+6.6 \pm 3.1 \%$ in the Modest-improvement group, and $+25.8 \pm 12.0 \%$ in the Marked-improvement group $(\mathrm{P}<0.0001)$. The change in $\mathrm{BNP}$ during the ET program was $+17.2 \pm 65.0 \%$, $-8.1 \pm 51.9 \%$, and $-34.2 \pm 44.4 \%$, respectively $(\mathrm{P}<0.0001)$, and had a significantly inverse relationship with the change in peak $\dot{\mathrm{VO}}_{2}(\mathrm{R}=-0.453, \mathrm{P}<0.0001)$ (Figure 1A). Similarly, the percentage change in $\dot{\mathrm{V}} / \mathrm{VCO}_{2}$ slope during the ET program was $+7.3 \% \pm 12.7 \%,-2.8 \% \pm 13.4 \%$, and $-7.0 \% \pm 14.0 \%$, respectively $(\mathrm{P}<0.0001)$, and inversely correlated with the change in peak $\mathrm{VO}_{2}(\mathrm{R}=-0.439, \mathrm{P}<0.0001)$ (Figure 1B).

\section{Clinical Outcomes According to Change in Exercise Capacity in High-BNP Patients}

In the High-BNP patients, clinical outcomes were compared according to tertiles of the change in peak $\mathrm{VO}_{2}$ during the ET program (Figure 2). The composite rate of all-cause death or HF hospitalization was significantly lower in the Marked-improvement group than in the Poor-improvement group (37.9\% vs. 54.4\%, respectively, $\mathrm{P}=0.036$ ), but there was no significant difference between the Marked-improvement group and the Modest-improvement group (37.9\% vs. $47.3 \%$, respectively, $\mathrm{P}=0.19)$, or between the Modest-improvement group and the Poorimprovement group $(\mathrm{P}=0.57)$ (Figure 2A).

In the univariate Cox regression analysis, LVDd, LVDs, LAD, hemoglobin, BNP, peak $\dot{\mathrm{VO}} 2$, and $\dot{\mathrm{VE}} / \dot{\mathrm{V} C O} 2$ slope 


\begin{tabular}{|c|c|c|c|c|c|}
\hline & \multicolumn{3}{|c|}{ Univariate } & \multicolumn{2}{|c|}{ Multivariate } \\
\hline & $X^{2}$ & $\mathrm{HR}(95 \% \mathrm{Cl})$ & $P$ value & $\mathrm{HR}(95 \% \mathrm{Cl})$ & $P$ value \\
\hline Age (years) & 0.60 & $1.01(0.98-1.05)$ & 0.44 & & \\
\hline Male & 1.7 & $1.90(0.74-6.44)$ & 0.20 & & \\
\hline IHD & 1.5 & $1.59(0.77-3.45)$ & 0.21 & & \\
\hline AF rhythm & 0.71 & $1.43(0.60-3.09)$ & 0.40 & & \\
\hline BMI & 0.17 & $0.98(0.87-1.10)$ & 0.68 & & \\
\hline LVDd (mm) & 4.7 & 1.05 (1.005-1.09) & 0.030 & $1.04(0.89-1.19)$ & 0.61 \\
\hline LVDs (mm) & 6.2 & $1.05(1.01-1.08)$ & 0.013 & $0.98(0.86-1.15)$ & 0.82 \\
\hline LVEF (\%) & 3.8 & $0.96(0.92-1.00)$ & 0.050 & $0.98(0.91-1.05)$ & 0.49 \\
\hline $\mathrm{LAD}(\mathrm{mm})$ & 5.9 & $1.05(1.01-1.09)$ & 0.016 & $1.04(0.99-1.08)$ & 0.14 \\
\hline Creatinine (mg/dL) & 6.4 & $2.64(1.26-5.25)$ & 0.011 & $1.31(0.51-3.17)$ & 0.57 \\
\hline Hemoglobin (g/dl) & 4.2 & $0.77(0.60-0.99)$ & 0.041 & $0.97(0.71-1.28)$ & 0.82 \\
\hline BNP (per 10-pg/mL) & 6.1 & $1.012(1.003-1.020)$ & 0.014 & $1.00(0.99-1.01)$ & 0.68 \\
\hline Baseline peak $\mathrm{VO}_{2}(\mathrm{~mL} / \mathrm{kg} / \mathrm{min})$ & 19.3 & $0.76(0.66-0.86)$ & $<0.0001$ & $0.77(0.63-0.93)$ & 0.0061 \\
\hline$\%$ Change in peak $\dot{\mathrm{VO}}_{2}(\%)$ & 6.9 & $0.97(0.94-0.99)$ & 0.0088 & $0.97(0.94-0.998)$ & 0.035 \\
\hline$\dot{\mathrm{VE}} / \dot{\mathrm{V}} \mathrm{CO}_{2}$ slope & 9.9 & $1.07(1.03-1.10)$ & 0.0017 & $1.03(0.97-1.09)$ & 0.34 \\
\hline ET session attendance (times) & 0.084 & $1.00(0.97-1.03)$ & 0.77 & & \\
\hline
\end{tabular}

High-BNP=BNP $\geq 200 \mathrm{pg} / \mathrm{mL}$. Abbreviations as in Tables 1,2,4.

at baseline and the change in peak $\mathrm{VO}_{2}$ during the ET program were all significantly related to the composite outcome, but age was not (Table 4). Multivariate analysis revealed that the change in peak $\dot{\mathrm{VO}}_{2}$ was a significant independent predictor of the combined endpoint after adjustment for baseline variables (Table 4). In addition, the prognostic impact of the change in peak $\dot{\mathrm{VO}}_{2}$ remained significant even after adjustment for the change in BNP $(\mathrm{P}=0.026)$ and after adjustment for the change in $\dot{\mathrm{V}} / \dot{\mathrm{V}} \mathrm{CO}_{2}$ slope $(\mathrm{P}=0.018)$. The change in $\mathrm{BNP}$ was also a significant independent predictor after adjustment for baseline variables $(\mathrm{P}=0.0001)$ and after adjustment for the change in peak $\dot{\mathrm{VO}}_{2}(\mathrm{P}=0.0041)$. The change in $\dot{\mathrm{V} E} / \dot{\mathrm{V} C O} 2$ slope was a significant independent predictor after adjustment for baseline variables $(\mathrm{P}=0.0036)$, but not after adjustment for the change in peak $\mathrm{VO}_{2}(\mathrm{P}=0.28)$.

All-cause death tended to be lower in the Markedimprovement group than in the Poor-improvement group (8.6\% vs. $24.6 \%$, respectively, $\mathrm{P}=0.056$ ), but no significant difference was observed between the Marked-improvement group and the Modest-improvement group (8.6\% vs. $20.0 \%$, respectively, $\mathrm{P}=0.10$ ) or between the Modestimprovement group and the Poor-improvement group $(\mathrm{P}=0.72)$ (Figure 2B). In the univariate $\mathrm{Cox}$ regression analysis, LVDd, LVDs, LAD, creatinine, hemoglobin, $\mathrm{BNP}$, peak $\dot{\mathrm{VO}}$, and $\dot{\mathrm{VE}} / \dot{\mathrm{VCO}}_{2}$ slope at baseline and the change in peak $\dot{\mathrm{VO}}_{2}$ during the ET program were all significantly related to all-cause death, but age was not (Table 5). In the multivariate analysis, the change in peak $\dot{\mathrm{VO}} 2$ was a significant independent predictor of all-cause death after adjustment for baseline variables (Table 5).

\section{Discussion}

The present study demonstrated that in advanced HF patients with $\mathrm{BNP} \geq 200 \mathrm{pg} / \mathrm{mL}$ and receiving current optimal medical therapy, the completion of a 3-month ET program significantly increased peak $\mathrm{VO}_{2}$, and a greater increase in peak $\dot{\mathrm{VO}}_{2}$ was associated with greater decreases in $\mathrm{BNP}$ level and $\dot{\mathrm{VE}} / \mathrm{VCO}_{2}$ slope and more favorable clinical outcomes. These findings suggested that even in such advanced HF patients, 'good responders' who achieve a greater improvement in exercise capacity by ET program have a greater improvement in hemodynamic status, ventilatory efficiency, and long-term outcomes than 'poor responders'. Furthermore, we found that the change in peak $\dot{\mathrm{VO}}_{2}$ during the ET program was a powerful independent predictor of clinical outcome, but did not significantly correlate with baseline characteristics, except for age. This finding indicated the difficulty in predicting 'good responders' in an ET program from the subjects' baseline characteristics and the prognostic importance of quantifying the response to ET program by serial CPX in the management of advanced HF patients.

Plasma BNP level is established as a reliable prognostic biomarker in HF patients. ${ }^{12,13}$ In consecutive HF patients who completed the 3-month ET program at our institution, half of them had a baseline BNP level $\geq 200 \mathrm{pg} / \mathrm{mL}$, and we confirmed that these High-BNP patients had more advanced HF characteristics, including LV diameter, LV function, exercise capacity, and ventilatory efficiency, and a higher prevalence of noncardiac comorbidities such as chronic kidney disease and anemia than the Low-BNP patients. Nevertheless, the elevation of BNP level was not associated with an attenuated improvement in exercise capacity during the 3-month ET program.

Because peak $\mathrm{VO}_{2}$ is an established powerful prognostic predictor in $\mathrm{HF}$ patients, ${ }^{\mathbf{3}, 16}$ the increase in peak $\mathrm{VO}_{2}$ during an ET program would be expected to contribute a favorable outcome. Indeed, the prognostic significance of changes in exercise capacity by ET program has been confirmed in the modern era of medical HF treatment including $\beta$-blockers. Tabet et al demonstrated in HF patients with $\mathrm{LVEF}<45 \%$ (mean age 53 years, LVEF $30 \%$, median BNP $331 \mathrm{pg} / \mathrm{mL}$, mean follow-up 16 months) that an improvement in exercise capacity after an ET program was a strong prognostic factor of cardiac events. ${ }^{17}$ In a substudy of the HF-ACTION (Heart Failure and a Controlled Trial Investigating Outcomes of Exercise Training) trial, ${ }^{9}$ Swank et al showed in HF patients with LVEF $\leq 35 \%$ 
(median age 59 years, LVEF 25\%, BNP not reported, median follow-up 30 months) that every $6 \%$ increase in peak $\dot{\mathrm{V}} \mathrm{O}_{2}$ was associated with an $8 \%$ lower risk of cardiovascular death or HF hospitalization. ${ }^{18}$ The present study extended the association between the efficacy of an ET program and clinical outcomes to older and more advanced HF patients receiving current optimal medical therapy ( $\beta$-blockers, 94\%) with LVEF $<45 \%$ and BNP $\geq 200 \mathrm{pg} / \mathrm{mL}$ (median age 68 years, LVEF 24\%, BNP $352 \mathrm{pg} / \mathrm{mL}$ ) and longer follow-up period (median 46 months).

Passino et al have previously shown a significant inverse relationship between changes in peak $\dot{\mathrm{VO}}_{2}$ and changes in $\mathrm{BNP}$ level during ET program in HF patients (mean LVEF $34 \%$, BNP $187 \mathrm{pg} / \mathrm{mL}) .{ }^{19}$ The present study confirmed this relationship in more advanced $\mathrm{HF}$ patients with higher baseline BNP level (mean LVEF 25\%, BNP $436 \mathrm{pg} / \mathrm{mL}$ ). Multiple potential mechanisms would be involved in the relationship. ET has been shown to improve LV diastolic function, ${ }^{20}$ autonomic nerve function, ${ }^{21}$ and endothelial function, ${ }^{22}$ all of which would contribute to alleviation of the hemodynamic burden imposed on the LV wall. Accordingly, patients who have a greater improvement in exercise capacity by ET would be likely to have a greater reduction in LV diastolic wall stress because of these beneficial effects, leading to a greater reduction in the BNP level.

An exaggerated ventilatory response to exercise, as expressed by elevated $\dot{\mathrm{V} E} / \dot{\mathrm{V} C O}{ }_{2}$ slope, is responsible for breathlessness and associated with poor prognosis in $\mathrm{HF}$ patients. ${ }^{23}$ Although the mechanism of excess ventilatory effort during exercise in HF patients is not completely understood, one of the potential mechanisms is enhanced ergoreflex activity, which accompanies the skeletal muscle myopathy in HF. ${ }^{\mathbf{2 4}}$ To the best of our knowledge, this is the first study to show a significant inverse relation between changes in peak $\dot{\mathrm{VO}}_{2}$ and changes in the $\dot{\mathrm{VE}} / \dot{\mathrm{VCO}}_{2}$ slope in $\mathrm{HF}$ patients during an ET program. This finding supports the notion that an improvement in a skeletal myopathy by ET would mitigate ergoreflex activation, leading to improved ventilatory efficiency. Another possible mechanism is that improvement in central hemodynamic function and ventilatory efficiency ${ }^{27}$ as a result of pharmacological treatment, not ET program, would be likely to have a positive effect on exercise capacity. However, the pharmacological treatment for HF, especially $\beta$-blockers, has been shown to have limited effect on exercise capacity. ${ }^{\mathbf{2 8 , 2 9}}$ Further studies are required to elucidate the precise mechanism of the relationship between changes in peak $\dot{\mathrm{VO}}_{2}$ and changes in $\mathrm{BNP}$ level or $\dot{\mathrm{VE}} / \mathrm{V}^{\mathrm{V} C O}{ }_{2}$ slope.

The mean extent of the increase in peak $\dot{\mathrm{VO}}_{2}(8.3 \%)$ in our High-BNP patients was lower than that reported by a meta-analysis including $1,240 \mathrm{HF}$ patients $(13.0 \%){ }^{30}$ This may be explained by the relatively high age (median, 68 years) and the modest intensity ET program (40-60\% of heart rate reserve) in our study. We observed no significant relationship between changes in peak $\mathrm{VO}_{2}$ and the number of attendances at supervised ET sessions. This is likely because the effect of the ET program is influenced by the total amount of ET including home ET, not assessed in this study. Further studies are needed to determine the most appropriate ET protocol regarding intensity, duration, frequency, and modality for achieving the greatest improvement in exercise capacity.

The safety of ET programs has been assessed in many studies. ${ }^{6}$ Smart et al reported no deaths that were directly related to exercise during more than 60,000 patient-hours of ET. ${ }^{7}$ Among our 340 advanced HF patients who completed the 3-month ET program, no ET-related deaths or adverse events, including worsening HF, were observed. Among the 115 patients who did not complete the program during the study period, no deaths occurred but 6 patients were hospitalized for worsening HF without any apparent relationship to ET during the 3-month program. Furthermore, we did not find any deterioration in renal function during the ET program even in High-BNP patients, a finding that is similar to the result that we previously reported in patients after acute MI. ${ }^{31}$

\section{Study Limitations}

First, it was a retrospective study involving a small number of patients without a control (non-exercise) group at a single institute. Although a prospective randomized study is essential to clarify the effect of ET programs on clinical outcomes in advanced HF patients, it would not be ethical to assign HF patients to a non-ET group at present when ET for HF patients is recommended in the guidelines. Second, we studied only the patients who had completed the 3-month ET program, which might have resulted in some bias towards a better outcome, because patients who dropped out of the ET program have been reported to have a worse outcome than those who completed such programs. ${ }^{32}$ Third, there might be some potentially important data for the assessment of outcome of HF patients, such as echocardiographic indices of LV diastolic function at baseline or change in LV function during the ET program, which were not available in the present study. Finally, we studied HF patients with reduced LVEF $(<45 \%)$, and therefore our findings cannot be generalized to HF patients with preserved LVEF.

\section{Conclusions}

In advanced HF patients with a high BNP level who completed a 3-month ET program, exercise capacity was significantly improved, similarly to those with a low BNP level, and a greater improvement in exercise capacity by the ET program was associated with greater decreases in $\mathrm{BNP}$ level and $\dot{\mathrm{VE}} / \mathrm{V} \mathrm{CO}_{2}$ slope and more favorable longterm clinical outcomes. These findings indicated that even advanced HF patients are likely to benefit from ET and should be referred to ET programs, and, conversely, that those with a poor improvement in exercise capacity during an ET program should be watched carefully for worsening outcomes.

\section{Acknowledgments}

The authors are grateful to Ayumi Otani and Keiko Katayama for technical support.

\section{Funding / Conflict of Interest}

None.

\section{References}

1. McMurray JJ, Packer M, Desai AS, Gong J, Lefkowitz MP, Rizkala AR, et al; PARADIGM-HF Investigators and Committees. Angiotensin-neprilysin inhibition versus enalapril in heart failure. N Engl J Med 2014; 371: 993-1004.

2. Cowie MR, Woehrle H, Wegscheider K, Angermann C, d'Ortho MP, Erdmann E, et al. Adaptive servo-ventilation for central sleep apnea in systolic heart failure. $N$ Engl J Med 2015; 373: 1095-1105. 
3. Mancini DM, Eisen H, Kussmaul W, Mull R, Edmunds LH Jr, Wilson JR. Value of peak exercise oxygen consumption for optimal timing of cardiac transplantation in ambulatory patients with heart failure. Circulation 1991; 83: 778-786.

4. Stevenson LW, Steimle AE, Fonarow G, Kermani M, Kermani D, Hamilton MA, et al. Improvement in exercise capacity of candidates awaiting heart transplantation. $\mathrm{J} \mathrm{Am} \mathrm{Coll} \mathrm{Cardiol}$ 1995; 25: $163-170$.

5. Florea VG, Henein MY, Anker SD, Francis DP, Chambers JS, Ponikowski P, et al. Prognostic value of changes over time in exercise capacity and echocardiographic measurements in pati ents with chronic heart failure. Eur Heart J 2000; 21: 146-153.

6. Coats AJ, Adamopoulos S, Radaelli A, McCance A, Meyer TE, Bernardi L, et al. Controlled trial of physical training in chronic heart failure: Exercise performance, hemodynamics, ventilation, and autonomic function. Circulation 1992; 85: 2119-2131.

7. Smart N, Marwick TH. Exercise training for patients with heart failure: A systematic review of factors that improve mortality and morbidity. Am J Med 2004; 116: 693-706.

8. Piepoli MF, Davos C, Francis DP, Coats AJ; ExTraMATCH Collaborative. Exercise training meta-analysis of trials in patients with chronic heart failure (ExTra-MATCH). BMJ 2004; 328: 189-196.

9. O'Connor CM, Whellan DJ, Lee KL, Keteyian SJ, Cooper LS, Ellis SJ, et al; HF-ACTION Investigators. Efficacy and safety of exercise training in patients with chronic heart failure: HFACTION randomized controlled trial. JAMA 2009; 301: $1439-1450$.

10. Yancy CW, Jessup M, Bozkurt B, Butler J, Casey DE Jr, Drazner MH, et al. 2013 ACCF/AHA guideline for the management of heart failure: A report of the American College of Cardiology Foundation/American Heart Association Task Force on practice guidelines. Circulation 2013; 128: e240-e327.

11. Ponikowski P, Voors AA, Anker SD, Bueno H, Cleland JG, Coats AJ, et al; Authors/Task Force Members. 2016 ESC Guidelines for the diagnosis and treatment of acute and chronic heart failure: The Task Force for the diagnosis and treatment of acute and chronic heart failure of the European Society of Cardiology (ESC): Developed with the special contribution of the Heart Failure Association (HFA) of the ESC. Eur Heart $J$ 2016; 37: 2129-2200.

12. Tsutamoto T, Wada A, Maeda K. Hisanaga T, Mabuchi N, Hayashi $\mathbf{M}$, et al. Plasma brain natriuretic peptide level as a biochemical marker of morbidity and mortality in patients with asymptomatic or minimally symptomatic left ventricular dysfunction: Comparison with plasma angiotensin II and endothelin-1. Eur Heart J 1999; 20: 1799-1807.

13. Anand IS, Fisher LD, Chiang YT, Latini R, Masson S, Maggioni $\mathrm{AP}$, et al; Val-HeFT Investigators. Changes in brain natriuretic peptide and norepinephrine over time and mortality and morbidity in the Valsartan Heart Failure Trial (Val-HeFT). Circulation 2003; 107: $1278-1283$

14. Takagi S, Sakuragi S, Baba T, Takaki H, Aihara N, Yasumura $\mathrm{Y}$, et al. Predictors of left ventricular remodeling in patients with acute myocardial infarcion participating in cardiac rehabilitation: Brain natriuretic peptide and anterior infarction. Circ J 2004; 68: 214-219.

15. Suzuki S, Takaki H, Yasumura Y, Sakuragi S, Takagi S, Tsutsumi $\mathrm{Y}$, et al. Assessment of quality of life with 5 different scales in patients participating in comprehensive cardiac rehabilitation after acute myocardial infarction. Circ J 2005; 69: 1527-1534.

16. Nakanishi M, Takaki H, Kumasaka R, Arakawa T, Noguchi T, Sugimachi M, et al. Targeting of high peak respiratory exchange ratio is safe and enhances the prognostic power of peak oxygen uptake for heart failure patients. Circ J 2014; 78: 2268-2275.
17. Tabet JY, Meurin P, Beauvais F, Weber H, Renaud N, Thabut $\mathrm{G}$, et al. Absence of exercise capacity improvement after exercise training program: A strong prognostic factor in patients with chronic heart failure. Circ Heart Fail 2008; 1: 220-226.

18. Swank AM, Horton J, Fleg JL, Fonarow GC, Keteyian S, Goldberg $\mathrm{L}$, et al; HF-ACTION Investigators. Modest increase in peak $\mathrm{VO}_{2}$ is related to better clinical outcomes in chronic heart failure patients: Results from heart failure and a controlled trial to investigate outcomes of exercise training. Circ Heart Fail 2012; 5: $579-585$.

19. Passino C, Severino S, Poletti R, Piepoli MF, Mammini C, Clerico A, et al. Aerobic training decreases B-type natriuretic peptide expression and adrenergic activation in patients with heart failure. J Am Coll Cardiol 2006; 47: 1835-1839.

20. Belardinelli R, Georgiou G, Cianci G, Berman N, Ginzton L, Purcaro A. Exercise training improves LV diastolic filling in patients with dilated cardiomyopathy. Circulation 1995; 91: $2775-2784$.

21. Roveda F, Middlekauff HR, Rondon MU, Reis SF, Souza M, Nastari L, et al. The effects of exercise training on sympathetic neural activation in advanced heart failure: A randomized controlled trial. J Am Coll Cardiol 2003; 42: 854-860.

22. Hambrecht R, Fiehn E, Weigl C, Gielen S, Hamann C, Kaiser $\mathrm{R}$, et al. Regular physical exercise corrects endothelial dysfunction and improves exercise capacity in patients with chronic heart failure. Circulation 1998; 98: 2709-2715.

23. Chua TP, Ponikowski P, Harrington D, Anker SD, Webb-Peploe $\mathrm{K}$, Clark AL, et al. Clinical correlates and prognostic significance of the ventilatory response to exercise in CHF. J Am Coll Cardiol 1997; 29: 1585-1590.

24. Clark AL, Piepoli M, Coats AJS. Skeletal muscle and the control of ventilation on exercise: Evidence for metabolic receptors. Eur J Clin Invest 1995; 25: 299-305.

25. Chua TP, Clark AL, Amadi AA, Coats AJ. The relationship between chemosensitivity and the ventilatory response to exercise in chronic heart failure. J Am Coll Cardiol 1996; 27: 650-657.

26. Piepoli M, Clark AL, Volterrani M, Adamopoulos S, Sleight P, Coats AJ. Contribution of muscle afferents to the hemodynamic, autonomic, and ventilatory responses to exercise in patients with chronic heart failure: Effects of physical training. Circulation 1996; 93: 940-952.

27. Agostoni P, Guazzi M, Bussotti M, De Vita S, Palermo P. Carvedilol reduces the inappropriate increase of ventilation during exercise in heart failure patients. Chest 2002; 122: 2062-2067.

28. Olsen SL, Gilbert EM, Renlund DG, Taylor DO, Yanowitz FD, Bristow MR. Carvedilol improves left ventricular function and symptoms in chronic heart failure: A double-blind randomized study. J Am Coll Cardiol 1995; 25: 1225-1231.

29. Demopoulos L, Yeh M, Gentilucci M, Testa M, Bijou R, Katz $\mathrm{SD}$, et al. Nonselective beta-adrenergic blockade with carvedilol does not hinder the benefits of exercise training in patients with congestive heart failure. Circulation 1997; 95: 1764-1767.

30. van Tol BA, Huijsmans RJ, Kroon DW, Schothorst M, Kwakkel G. Effects of exercise training on cardiac performance, exercise capacity and quality of life in patients with heart failure: A metaanalysis. Eur J Heart Fail 2006; 8: 841-850.

31. Takaya Y, Kumasaka R, Arakawa T, Ohara T, Nakanishi M, Noguchi T, et al. Impact of cardiac rehabilitation on renal function in patients with and without chronic kidney disease after acute myocardial infarction. Circ $J$ 2014; 78: 377-384.

32. Martin BJ, Hauer T, Arena R, Austford LD, Galbraith PD, Lewin AM, et al. Cardiac rehabilitation attendance and outcomes in coronary artery disease patients. Circulation 2012; 126: $677-687$. 